influenza vaccine declination rate for the 2020-2021 influenza season. This information may provide guidance on target groups that may benefit from vaccine education to alleviate apprehension regarding vaccine efficacy and safety.

This study has several limitations. A high proportion of HCP did not complete the annual seasonal flu survey. HCP who were preemployment, part-time workers, and/or contractors were included to complete the annual seasonal flu survey, and it is possible that they may have received their influenza vaccine elsewhere. Although race and ethnicity have been shown to be contributing factors to vaccine hesitancy, we were unable to obtain these data due to the limitations of our employee health system. Finally, the annual seasonal flu survey did not capture data for determining whether factors related to the COVID-19 pandemic may have contributed to the decline in influenza vaccination uptake and increase in incomplete surveys. It remains unclear whether the decline in influenza vaccination uptake will remain sustained in years to come, and additional studies will be necessary to determine the specific impact of COVID-19 on increased declination of influenza vaccination.

\section{Acknowledgments.}

Financial support. No financial support was provided relevant to this article.

\section{References}

1. Wilde JA, McMillan JA, Serwint J, et al. Effectiveness of influenza vaccine in healthcare professionals: a randomized trial. JAMA 1999;281:908-913.

2. Ahmed F, Lindley MC, Allred N, et al. Effect of influenza vaccination of healthcare personnel on morbidity and mortality among patients: systematic review and grading of evidence. Clin Infect Dis 2014;58:50-57.

3. Influenza vaccination information for health care workers. Centers for Disease Control and Prevention website. https://www.cdc.gov/flu/professionals/health careworkers.htm. Accessed January 5, 2021.

4. Quan K, Tehrani DM, Dickey L, et al. Voluntary to mandatory: evolution of strategies and attitudes toward influenza vaccination of healthcare personnel. Infect Control Hosp Epidemiol 2012;33:63-70.

5. Centers for Disease Control and Prevention (CDC). Interventions to increase influenza vaccination of health-care workers-California and Minnesota. Morb Mortal Wkly Rep 2005;54:196-199.

6. Honda H, Sato Y, Yamazaki A, et al. A successful strategy for increasing the influenza vaccination rate of healthcare workers without a mandatory policy outside of the United States: a multifaceted intervention in a Japanese tertiary care center. Infect Control Hosp Epidemiol 2013;34:1194-200.

7. Dror AA, Eisenbach N, Taiber S, et al. Vaccine hesitancy: the next challenge in the fight against COVID-19. Eur J Epidemiol 2020;35:775-779.

8. Gagneux-Brunon A, Detoc M, Bruel S, et al. Intention to get vaccinations against COVID-19 in French healthcare workers during the first pandemic wave: a cross-sectional survey. J Hosp Infect 2021;108:168-173. article.

\title{
Coronavirus disease 2019 (COVID-19) vaccinations and preservation of the healthcare workforce
}

\author{
Gabriela M. Andujar Vazquez ${ }^{1}$ (1), Jonathan Morely MPH${ }^{2}$, Helen W. Boucher MD ${ }^{1}$ and Shira I. Doron MD ${ }^{1}$ \\ ${ }^{1}$ Division of Geographic Medicine and Infectious Diseases, Department of Medicine, Tufts Medical Center, Boston, Massachusetts and ${ }^{2}$ Department of Emergency \\ Management, Tufts Medical Center, Boston, Massachusetts
}

To the Editor-Healthcare facilities have been stressed to their limits throughout the coronavirus disease 2019 (COVID-19) pandemic due to the combination of surges of patients and staffing shortages. US hospitals began vaccinating staff against COVID-19 exactly 4 months ago in mid-December 2020.

Tufts Medical Center, an urban 350-bed academic medical center with $\sim 7,400$ employees, began vaccinating staff with BNT162b2 vaccine (Pfizer) on December 16, 2020. On December 28,2020 , we incorporated the mRNA-1273 (Moderna) vaccine into our employee vaccination clinic. Gradually increasing eligibility to more groups, on January 26, 2021, eligibility was opened to all employees, including those working remotely. To date, 6,044 employees have been vaccinated with 2 doses of mRNA vaccine.

In total, 641 employees (including those working fully remotely), contractors, volunteers, interns, and students were

Author for correspondence: Gabriela M. Andujar Vazquez, E-mail: gandujarvazquez@ tuftsmedicalcenter.org

Cite this article: Andujar Vazquez GM, et al. (2022). Coronavirus disease 2019 (COVID-19) vaccinations and preservation of the healthcare workforce. Infection Control \& Hospital Epidemiology, 43: 1305-1306, https://doi.org/10.1017/ice.2021.238 infected with COVID-19 between March 16, 2020, and May 3,2021 . A precipitous drop in infections was observed after these healthcare workers began to receive their second doses of mRNA vaccine (Fig. 1). ${ }^{1}$ At its highest point, 90 employees were simultaneously out of work due to COVID-19-related illness. At the time of this writing, only 19 employees are out due to COVID-19, even though the incidence of COVID-19 remains high in the surrounding community.

We established a telephone hotline for employees, who were also encouraged to visit the employee health department as needed to report and discuss vaccine side effects. In total, 150 employees reported side effects, of which 12 met the criteria to be reported to the Vaccine Adverse Event Reporting System.

Our hospital continues to operate at or above capacity, not only due to COVID-19 admissions but also to the increasing acuity of illness in patients without COVID-19, possibly due to delays in care. Vaccination has enabled us to preserve our workforce and provide necessary care to patients. When first introduced, many healthcare workers, trusting the data that supported the emergency use authorization, signed up to be vaccinated despite what was for some a natural trepidation associated with the idea of a "new" 
(a) Employee Infections and Vaccinations per Week

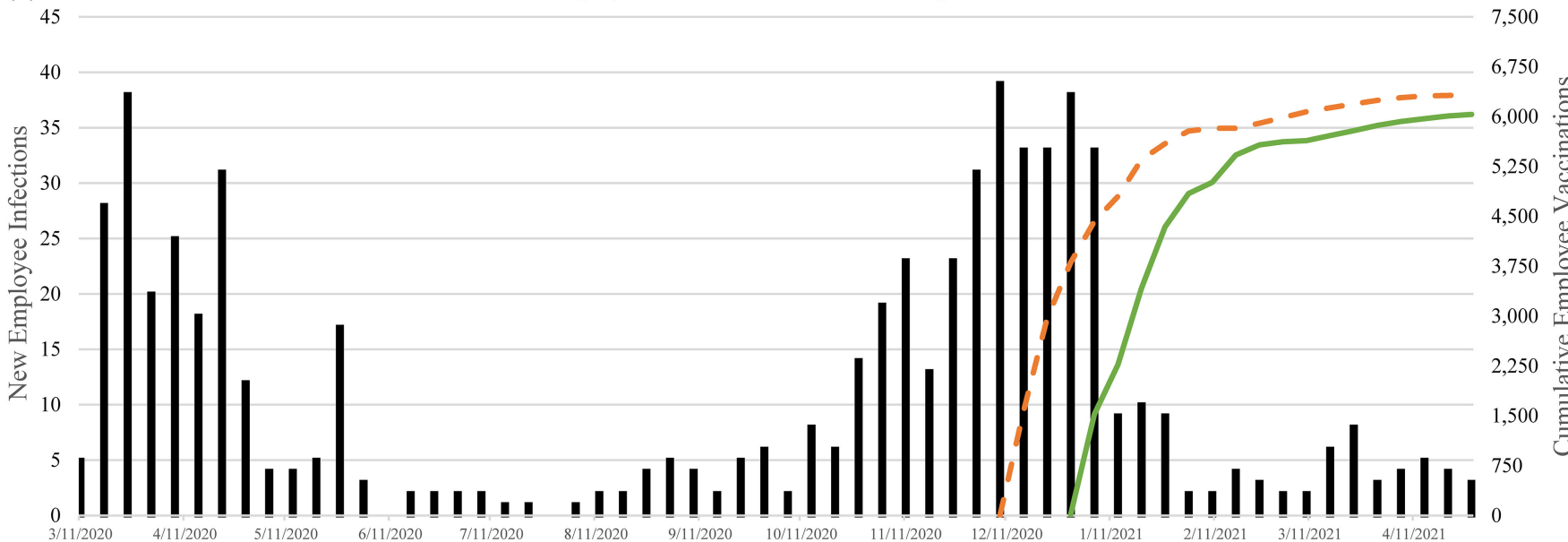

Employee Infections $\quad-\quad-$ Employee Dose 1 Employee Dose 2

(b)

Massachusetts Infections and Vaccinations per Week

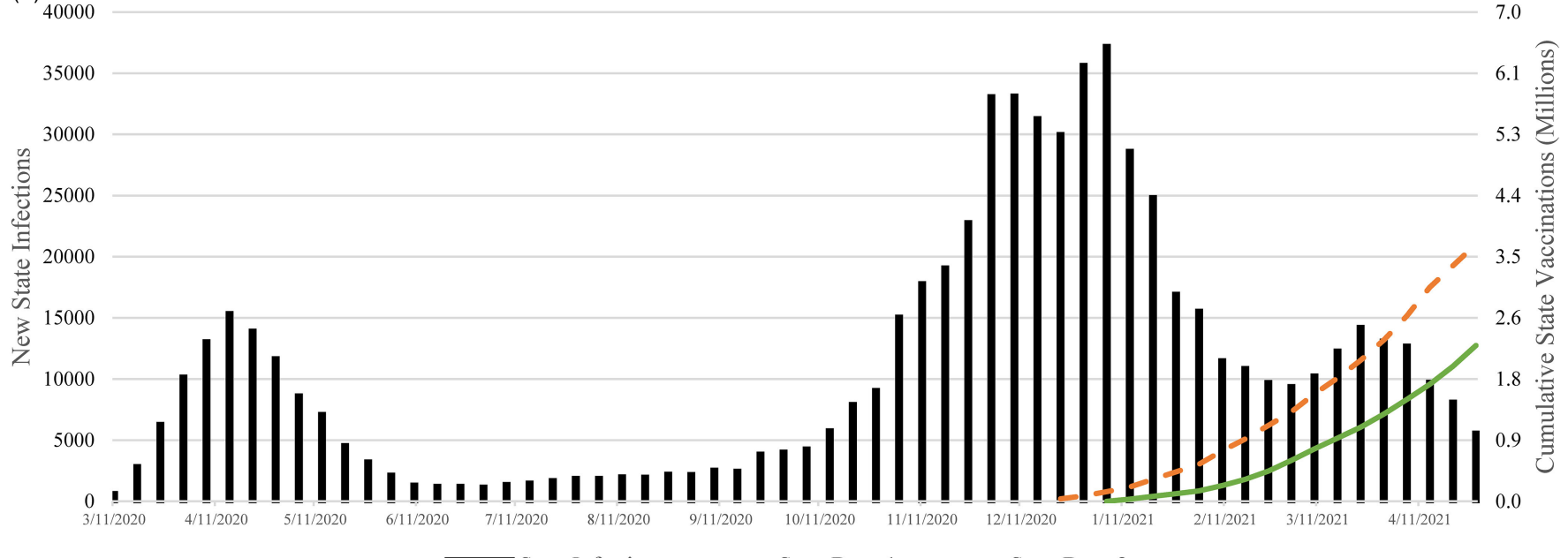

State Infections $\quad-\quad-$ State Dose $1 \longrightarrow$ State Dose 2

Figure 1. (a) COVID 19 Employee Infections and Vaccinations per week (b) The State of Massachusetts Infections and Vaccinations per Week.

vaccine. Today, our real-world experience and that of others ${ }^{2}$ mirrors that of the clinical trials demonstrating the safety and efficacy of mRNA vaccines against COVID-19. Given that staffing constraints caused by COVID-19 are a patient safety issue and that staff-to-staff transmission of COVID-19 has been documented frequently, ${ }^{3,4}$ and staff-to-patient transmission more rarely, ${ }^{3,4}$ we believe that healthcare workers have a duty to be vaccinated.

\section{Acknowledgments.}

Financial support. No financial support was provided relevant to this article.

Conflicts of interest. All authors report no conflicts of interest relevant to this article.

\section{References}

1. Bureau of Infectious Diseases and Laboratory Sciences. COVID 19 data. Massachusetts Department of Public Health website. https://www. mass.gov/info-details/covid-19-response-reporting. Accessed May 7, 2021.

2. Benenson S, Cohen M, Nir-Paz Ran. BNT162b2 mRNA COVID-19 vaccine effectiveness among healthcare workers. N Engl J Med 2021;384: 1775-1777.

3. Klompas M, Baker M, Rhee $\mathrm{C}$, et al. A SARS-CoV-2 cluster in an acute-care hospital. Ann Intern Med 2021. doi: 10.7326/M20-7567.

4. Klompas M, Baker M, Griesbach D, et al. Transmission of SARS-CoV-2 from asymptomatic and presymptomatic individuals in healthcare settings despite medical masks and eye protection. Clin Infect Dis 2021. doi: 10.1093/cid/ ciab218. 